\title{
Melaib Mebase Tegeh: Bentuk Perkawinan Yos Embang
}

\author{
Ni Wayan Sumarjayanti, I Nyoman Sama, I Ketut Darmana \\ Program studi Antropologi, Fakultas Ilmu Budaya, Unud \\ [yantihp24@gmail.com], [nyoman.sama@unud.ac.id], [ketut_darmana@yahoo.com] \\ Denpasar, Bali, Indonesia \\ *Corresponding Author
}

\begin{abstract}
Pedawa village is part of Banjar district, Buleleng regency, which is one of the Bali AgaVillages in the north Bali. Pedawa as the old village has its own uniqueness especially concerning the marriage ceremony in which the local people in that place often called it as Melaib. There are six types of marriages in Desa Pedawa namely melaib ngemaling, melaib ngidih, melaib ngangken, melaib negteg, melaib mebase tegeh, melaib ngerorod (mepekirang).Melaib mebase tegeh is one of the types of marriage for the people of Pedawa Village who shelter Yos Embang which is the procession of the marriage ceremony uses the conditions in the form of banten base tegeh as a symbol for every woman from Yos Embang (local kawitan) who marries out of their clan. The results of this research are expected to provide benefits and development of science in the field of anthropology, especially about marriage. The results of this research showed that melaib mebase tegeh is one of the types of marriage in Pedawa Village, which is implemented by the people in Pedawa vilage that shelter Yos Embang if the women mated out from Yos Embang. Melaib mebase tegeh has the meaning of kinship, religious meaning and cultural. Moreover, if the people who marry girls from Yos Embang do not carry out mebase tegeh ceremony will have an impact on family and community life and have an impact on the belief aspect of the people in Pedawa Village, which shelter Yos Embang.
\end{abstract}

Keywords: Mebase Tegeh, Marriage, Yos Embang

\begin{abstract}
Abstrak
Wilayah Desa Pedawa termasuk Kecamatan Banjar, Kabupaten Buleleng yang merupakan salah satu Desa Bali Aga yang ada di belahan Bali Utara.Sebagai desa tua Pedawa juga memiliki keunikan tersendiri terutama menyangkut upacara perkawinan yang istilah lokal sering disebut Melaib.Jenis-jenis perkawinan di Desa Pedawa ada enam yaitu melaib ngemaling, melaib ngidih, melaib ngangken, melaib negteg, melaib mebase tegeh, melaib ngerorod (mepekirang). Melaib mebase tegehmerupakan salah satu jenis perkawinan bagi masyarakat Desa Pedawa yang menyungsung Yos Embang dimana dalam prosesi upacara perkawinan ini menggunakan syarat berupa banten base tegeh sebagai simbol bagi setiap perempuan yang berasal dari Yos Embang (kawitan lokal) yang menikah keluar dari klen mereka.Hasil penelitian ini diharapkan dapat memberikan manfaat dan pengembangan ilmu pengetahuan di bidang antropologi, yaitu tentang perkawinan.Hasil penelitian menunjukkan bahwa melaib mebase tegeh merupakan salah satu jenis perkawinan yang ada di Desa Pedawa dimana yang melaksanakan melaib mebase tegeh adalah masyarakat Desa Pedawa yang menyungsung Yos Embang jika anak perempuan mereka kawin keluar dari Yos Embang.Melaib mebase tegeh memiliki makna kekerabatan, makna religi serta makna budaya. Adapun dampak yang ditimbulkan bagi masyarakat yang mengambil atau
\end{abstract}


mempersunting anak perempuan dari Yos Embang jika tidak melaksanakan upacara melaib mebase tegeh yaitu akan berdampak terhadap kehidupan keluarga dan masyarakat serta berdampak pada aspek sistem kepercayaan masyarakat Desa Pedawa yang menyungsung Yos Embang.

\section{Kata Kunci: Mebase Tegeh, Perkawinan, Yos Embang}

\section{PENDAHULUAN}

Salah satu fase penting hidup manusia dalam bermasyarakat adalah perkawinan.Dikatakan penting, karena perkawinan dapat mengubah status hukum seseorang, sebelum melaksanakan upacara perkawinan mereka biasanya disebut deha/truna.Apabila seseorang telah melangsungkan perkawinan dalam budaya Bali biasanya disebut alaki rabiatau mapakurenan. Oleh karena itu, dari sudut pandang yuridis dan sosiologi akan mengakibatkan terjadinya perubahan status seseorang, baik dalam lingkup banjar maupun desa pakraman(Windia, 2009:1).Dalam kebudayaan manusia perkawinan merupakan pengatur tingkah manusia yang berkaitan dengan kehidupan kelaminnya. Selainsebagai pengatur kelakuan seksual, perkawinan mempunyai berbagai fungsi dalam kehidupan masyarakat manusia yaitu, memberi perlindungan kepada anak-anak hasil perkawinan, memenuhi kebutuhan akan harta, gengsi, tetapi juga untuk memelihara hubungan baik degan kelompok-kelompok kerabat tertentu (Cun Bay, 2015:2).

Setiap perkawinan tidak hanya didasarkan kepada kebutuhan biologis antara pria dan wanita yang diakui sah, melainkan sebagai pelaksana proses kodrat hidup manusia (Jurnal Santoso: 1). Dalam ajaran Agama Hindu, masyarakat Bali mengenal suatu istilah yang disebut dengan "Catur Asrama" yang merupakan empat tahapan dalam menjalankan kehidupan di dunia. Grahastamerupakan tahapan kedua dalam kehidupan masyarakat Bali yang berarti kehidupan di dalam berumah tangga dengan terselenggaranya prosesi upacara pernikahan atau yang sering disebut dengan "pawiwahan" di Bali (Pramana, 2019:2).

Dasar dalam sebuah perkawinan itu dibentuk oleh suatu unsur alami dari diri manusia itu sendiri yang meliputi kebutuhan hidup berumah tangga, kebutuhan biologis untuk melahirkan keturunan, kebutuhan terhadap kasih sayang antaranggota keluarga, dan juga kebutuhan rasa persaudaraan serta kewajiban untuk memelihara anak-anak agar menjadi penerus generasi dan menjadi anggota masyarakat yang baik (Pratama, 2018:2)

Upacara perkawinan merupakan saat yang paling menentukan kesahan perkawinan tersebut, apakah perkawinan tersebut sesuai dengan adat atu tidak bagi masyarakat setempat dan juga ditentukan lewat terselenggaranya adat pada sebelum upacara perkawinan, saat upacara perkawinan, dan sesudah upacara perkawinan, karena dengan terlaksananya upacara perkawinan ini maka akan dianggap merupak perkawinan yang ideal dan memiliki nilai tinggi bagi masyarakat yang melaksanakannya (Sipayung, 2015:2).

Wilayah Desa Pedawa termasuk Kecamatan Banjar, Kabupaten Buleleng merupakan salah satu Desa Bali Aga yang ada di belahan Bali Utara.Sebagai desa tua Pedawa juga memiliki keunikan tersendiri, terutama menyangkut dalam upacara perkawinan yang istilah lokal sering disebut melaib.Jenis-jenis perkawinan di Desa Pedawa ada enam yaitu melaib ngemaling, melaib ngidih, melaib ngangken, melaib negteg, melaib 
mebase tegeh, melaib ngerorod (mepekirang).

Masyarakat Desa Pedawa yang menyungsung Yos Embang terkait dengan rangkaian prosesi perkawinan pihak keluarga mempelai laki-laki harus mengikuti salah satu ketentuan adat yang lazim disebut mebase tegeh.Artinya perkawinan mebase tegeh ini dilaksanakan pada saat prosesi ngunye ke rumah mempelai perempuan.Hal ini didasari karena Yos Embang Desa Pedawa zaman dulu sangat sulit memiliki anak perempuan, dalam hal ini Yos Embang masih memiliki kepercayaan terhadap mitos tersebut. Berdasarkan uraian dan pemaparan yang ada maka penelitian ini mengetengahkan judul "Melaib Mebase Tegeh: Bentuk Perkawinan Yos Embang.

Berdasarkan uraian latar belakang di atas dapat mengedepankan dua pokok permasalahan sebagai berikut: Bagaimana bentuk Perkawinan Yos Embang di Desa Pedawa, Kecamatan Banjar, Kabupaten Bueleng, Bali?, Bagaimana makna dan dampak mebase tegeh dalam upacara perkawinan Yos Embang di Desa Pedawa, Kecamatan Banjar, Kabupaten Buleleng, Bali?

Adapun tujuan yang dicapai dalam penelitian ini adalah sebagai berikut: Untuk mengetahui bentuk perkawinan Yos Embang di Desa Pedawa, Kecamatan Banjar, Kabupaten Buleleng, Untuk mengetahui makna dan dampak dari mebase tegeh dalam upacara perkawinan Yos Embang di Desa Pedawa, Kecamatan Banjar, Kabupaten Buleleng.

\section{METODE}

Penelitian ini menggunakan metode penelitian kualitatif. Menurut Heriyawati (2016:72), penelitian kualitatif adalah penelitian yang tidak menggunakan model-model matematika, statistik, atau komputer. Penelitian kualitatif, informasi yang dikumpulkan dan diolah harus tetap objektif dan tidak dipengaruhi oleh pendapat sendiri.

Penelitian ini dilakukan di Desa Pedawa Kecamatan Banjar Kabupaten Buleleng.Jenis data yang digunakan dalam penelitian ini adalah data kualitatif.Sumber data yang digunakan yaitu sumber data primer yang diperoleh melalui observasi dan wawancara.serta sumber data sekunder yang diperoleh melalui studi pustaka.

\section{HASIL DAN PEMBAHASAN}

\section{Bentuk Perkawinan Yos Embang di Desa Pedawa}

\section{a. Asal-usul Melaib Mebase Tegeh}

Sampai saat ini masyarakat Desa Pedawa tidak memiliki catatan mengenai sejarah asal-usul keberadaan perkawinan melaib mebase tegeh di Desa Pedawa.Namun, ada cerita atau mitos mengenai asal-usul melaib mebase tegeh tetapi belum bisa dipastikan mengenai kebenaran cerita atau mitos tersebut. asalusul melaib mebase tegeh adalah berawal dari ada seseorang yang berasal dari Yos Embang mengalami musibah yang diakibatkan oleh seorang perempuan dan mengalami sulitnya memiliki keturunan perempuan, maka munculah pemikiran jika nanti mempunyai keturunan perempuan pada saat prosesi upacara perkawinannya akan dibuatkan upacara mebase tegeh jika anak perempuan mereka menikah keluar dari Yos Embang.

\section{b. Melaib Mebase Tegeh}

Hukum adat di Bali mengenal dua cara melangsungkan perkawinan yaitu kawin dengan cara memadik (meminang) dan kawin dengan cara ngerorod (lari bersama) (Firmansyah, 2017:2-3).

Berbeda dengan masyarakat di Desa Pedawa jenis-jenis perkawinan yang ada yaitu melaib ngemaling, melaib ngidih, melaib ngangken, melaib negteg, melaib 
mebase tegh, melaib ngerorod. Perkawinan mebase tegeh merupakan salah satu jenis perkawinan yang ada di Desa Pedawa, dalam sejarah Pedawa diceritakan bahwa perkawinan ini biasa disebut dengan Melaib Mebase Tegeh.Dalam masyarakat Desa Pedawa yang melaksanakan perkawinan mebase tegeh ini hanya masyarakat yang menyungsung Yos Embang.Rangkaian mebase tegeh harus berjalan berjejer dan banten utama yaitu base tegeh yang di depan dibawa oleh anak-anak yang berusia rata-rata 7 tahun karena dipercaya oleh masyarakat setempat bahwa anakanak masih suci dan tidak punya dosa. Melaib mebase tegeh dilaksanakan pada saat tahap akhir dari rangkaian upacara perkawinan yaitu pada saat nguye ke rumah mempelai perempuan.

\section{c. Bentuk Banten Base Tegeh dalam Perkawinan Yos Embang}

Prosesi dalam upacara perkawinan memiliki tata cara yang bervariasi sesui tradisi dalam masyarakat, dan setiap kebudayaan memiliki cara untuk memaknai perkawinan itu sendiri (Dade, 2012: 1).

Pada dasarnya masyarakat Yos Embang Desa Pedawa mengartikan banten base tegeh sebagai suatu simbol wujud pengganti anak perempuan mereka yang kawin keluar dari Yos Embang yang harus diserahkan oleh pihak keluarga laki-laki kepada keluarga perempuan yang akan dikawini demi memperistri perempuan itu secara sah.banten base tegeh dengan menggunakan daun sirih sebagai sarana utama, base tegeh merupakan daun sirih yang dirangkai sedemikian rupa berjejer ke atas menyerupai wujud manusia yang disimbolkan sebagai pengganti mempelai perempuan. Daun sirih yang dirangkai berjejer ke atas memakai wadah dulang yang berisi uang kepeng1 pocong kemudian memakai sumbul yang dirangkai langsung dengan daun sirih.

\section{d. Proses Melaib Mebase Tegeh}

Semua makhluk di dunia ini diciptakan oleh Sang Pencipta yang dibentuk juga dengan material sehingga kelihatan ada kehidupan di dunia ini, oleh karena itu bagi umat Hindu ada hubungan timbal balik dengan membuat upakara sebagai persembahan kehadapan Sang Pencipta. Tampak terlihat dalam salah satu proses persembahan yadnya yang dilaksanakan oleh masyarakat Desa Pedawa yang menyungsung Yos Embang pada upacara perkawinan mebase tegeh. Dalam setiap pelaksanaan upacara perkawinan bagi umat Hindu, tidak mengabaikan adat yang telah ada dalam masyarakat. Begitu juga dengan adat perkawinan mebase tegeh di Desa Pedawa yang dilaksanakan melalui beberapa tahap. Adapun tahap-tahapnya yaitu: Pertama Tahap Persiapan, Pada tahap persiapan ini dilaksanakan perkawinan biasa atau perkawinan pada umumnya Desa Pedawa, tetapi setelah itu pernikahan tersebut belum dianggap sah karena belum melaksanakan upacara mebase tegeh.Proses pertama yang harus di lalui oleh calon pengantin adalah tahap persiapan dalam tahap ini dilaksanakan perkawinan biasa atau perkawinan pada umumnya pada masyarakat Desa Pedawa misalnya seperti melaib ngemaling (kawin lari) atau melaib ngidih (meminang). Selanjutnya, belum selesai hanya tahap mengambil saja dulu yang dalam istilah Pedawa disebut mengkeb.Mengkeb berarti belum mendapatkan jalan terang dari keluarga pihak perempuan.Berikutnya baru, dilaksanakan ngeleledin yang artinya datang ke rumah mempelai perempuan berturut-turut sampai pihak kelurga perempuan memberikan jalan atau waktu untuk melaksankan mebase tegeh. 
Selanjutnya kedua Tahap Penyelesaian, Tahap penyelesaian ini merupakan tahap akhir dari rangakain upacara perkawinan masyarakat Desa Pedawa yang menyungsung Yos Embang artinya dalam tahap penyelesaian ini dilaksanakan ngunye ke rumah mempelai perempuan dimana pihak keluarga lakilaki wajib membawa sarana banten base tegeh ke rumah keluarga perempuan. Tahap ini merupakan tahap berlangsungnya perkawinan mebase tegeh.Wujud banten base tegeh merupakan suatu simbol pengganti anak perempuannya yang menikah keluar dari Yos Embang.

\section{Makna dan Dampak Melaib Mebase Tegeh pada Upacara Pekawinan Yos Embang di Desa Pedawa}

\section{Makna Mebase Tegeh pada Upacara Perkawinan Yos Embang}

Untuk mengungkap yang disebut makna kebudayaan, perlulah mengetahui lebih dahulu cara menafsir simbol-simbol yang setiap saat dan tempat dipergunakan orang dalam kehidupan umum. Pendayagunaan makna dari simbol sesungguhnya tidaklah terbatas pada upacara, mitos, cerita, legenda dan lainlain yang dianggap resmi atau adiluhung saja.Mengingat bahwa simbol budaya adalah kendaraan pembawa makna, Geertz berkesimpulan bahwa selama ini sistem simbol yang tersedia di kehidupan umum sebuah masyarakat sesungguhnya menunjukkan bagaimana para warga masyarakat yang bersangkutan melihat, merasa, dan berfikir tentang dunia mereka dan bertindak berdasarka nilainilai yang sesuai (Geertz, 1992:vi-vii). Adapun makna yang terkandung pada upacara melaib mebase tegeh pada masyarakat yang menyungsung Yos Embang di Desa Pedawa: a. Makna Kekerabatan Mebase Tegeh pada Upacara Perkawinan Yos Embang

Kehidupan masyarakat Bali bersifat komunal terlihat pada kegiatan menyama braya dalam lingkungan keluarga hingga desa pakraman. Menyama Braya adalah kegiatan bergotong royong untuk menyelenggarakan acara tertentu (Dharmapatni: 2016: 5). Perkawinan sangat terkait dengan sistem kekerabatan yang dapat dilihat berdasarkan garis keturunan

2013:2).Kekerabatan

(Kusmirayani, merupakan keterjalinan sebuah hubungan persaudaraan atau kekeluargaan yang terjalin antara keluarga pihak laki-laki dan keluarga pihak perempuan.

Upacara melaib mebase tegeh merupakan salah satu cara untuk membina hubungan kekerabatan. Wujud dan nilai persaudaraan sangat terlihat pada sanak keluarga datang untuk terlibat dalam pelaksanaan perkawinan mebase tegeh, sebelum dilaksanakannya upacara mebase tegeh sanak keluarga dan kerabat berkumpul untuk gotong royong menyiapkan dan membuat sarana banten yang digunakan pada saat upacara melaib mebase tegeh.Seluruh rangkaian prosesi upacara melaib mebase tegeh di Desa Pedawa dilakukan untuk tuhuan bersama. Makna kebersamaan merupakan suatu konsep cara pandang yang tidak dapat dipisahkan dengan kehidupan kelompok masyarakat dalam menjalankan aktifitas sehari-hari (Pramana, 2017:98).

b. Makna Religi Mebase Tegeh pada Upacara Perkawinan Yos Embang

Hartawan (2017:155) menyatakan bahwa sistem religi berwujudkan aktivitas dan tindakan manusia dalam melaksankan kebaktiannya kepada Tuhan, para dewa, roh nenek moyang, atau makhluk halus berkomunikasi dengan Tuhan dan penghuni gaib lainnya. 
Sistem religi dan upacara dalam suatu religi berwujud aktivitas dan tindakan manusia dalam melaksanakan kebaktiannya kepada Tuhan, dewa-dewa, roh nenek moyang, atau makhluk halus lain, dalam usahanya untuk berkomunikasi dengan Tuhan dan penghuni alam gaib lainnya.Upacara religi atau upacara keagamaan itu dilaksanakan pada tempat tertentu, saat tertentu, dilaksanakan dan dipimpin oleh orang tertentu.

Sebuah jurnal hasil penelitian dari Riski Dwi Purwandari dkk (2014) emaparkan tentang simbol dan makna pernikahan adat Jawa yaitu seperti upacara siraman maknanya yaitu untuk membersihkan diri dari hal-hal yang kotor dan negatif. Pada masyarakat Desa Pedawa yang menyungsung Yos Embang mempunyai anggapan atau pandangan yang sampai saat ini masih menjadi kepercayaannya yaitu upacara melaib mebase tegeh yangmerupakan sebuah kewajiban yang harus dilaksanakan oleh setiap laki-laki yang mengambil atau menikah dengan anak perempuan dari Yos Embang. Makna religi berkaitan erat dengan upaya untuk memupuk, menumbuhkan, dan mengembangkan kehidupan masyarakat yang mencerminkan keyakinan beragama berdasarkan sastra agama.Sistem kekerabatan dan perkawinan sangat menentukan sangat menentukan keberlangsungan tatanan adat-istiadat serta struktur sosialnyasecara harmonis (Manalu, 2013:1).

Upacara mebase tegeh menurut masyarakat Desa Pedawa yang menyungsung Yos Embang memiliki kesakralan tersendiri, sehingga pada saat anak perempuan mereka menikah keluar dari Yos Embang maka dari pihak lakilaki harus diwajibkan untuk melaksanakan upacara mebase tegeh karena didalam banten base tegeh tersebut mengandung simbol pengganti anak perempuan mereka.. Oleh karena itu, Upacara mebase tegeh tersebut sangat disakralkan oleh masyarakat yang menyungsung Yos Embang karena kepercayaan masyarakat terhadap hal-hal niskala membuat mereka sadar bahwa seberapa pentingnya untuk melaksanakan upacara mebase tegeh sebagai tahap akhir dari rangkaian upacara perkawinan.

c. Makna Budaya Mebase Tegeh pada Upacara Perkawinan Yos Embang

Makna budaya yang ada di dalam masyarakat dibentuk oleh tradisi yang berkembang di tempat mereka tinggal dan sekelompok masyarakat secara bersama-sama terlibat dalam melestarikan atau melaksanakan suatu kebiasaan-kebiasaan yang dimaksud sehingga membentuk konsepsi, yaitu sebagai pembawa arti atau rancangan yang telah ada dalam pikiran manusia.Dapat disimpulkan bahwa maknanya adalah tradisi yang ada mengandung nilai luhur yang merupakan adat kebiasaan yang selalu diyakini secara turun temurun oleh masyarakat setempat.

Begitu juga dalam upacara melaib mebase tegeh yang terdapat di Desa Pedawa hingga saat ini masih tetap dipertahankan dan dilaksanakan keberadaannya, yang didasari atas dasar kepercayaan dan sejarah yang dimiliki sangat kuat sehingga sangat berdampak sekali bagi kehidupan masyarakat Desa Pedawa yang menyungsung Yos Embang. Makna budaya yang terkandung dalam dilaksankannya upacara melaib mebase tegeh sesuai dengan amanat yang telah diwariskan secara turun temurun oleh leluhur masyarakat yang menungsung Yos dapat dijadikan patokan dan acuan bagi generasi muda penerus Desa Pedawa khususnya bagi masyarakat yang menyungsung Yos Embang agar tidak melakukan pernikahan secara dini, 
karena mengingat dilihat dari proses dan biaya yang begitu besar.

\section{Dampak Melaib Mebase Tegeh}

a. Dampak Mebase Tegeh terhadap Kehidupan Keluarga dan Masyarakat Dampak terhadap keluarga merupakan dampak yang dirasakan secara internal, dimana dampak ini langsung dirasakan oleh masyarakat Desa Pedawa yang menyungsung Yos Embang sendiri terutama kepada keluarga inti.dampak jika tidak melaksanakan upacara mebase tegeh dalam kehidupannya dimasa mendatang akan tidak bagus, ada keturunannya cacat, sakit malahan ada sakit bertahun-tahun sampai meninggal. Selanjutnya sebagai dampak eksternal yaitu dampak terhadap masyarakat yang merupakan dampak yang tidak langsung. Dari segi skala orang tersebut akan menjadi kecue yaitu istilah lokal dari masyarakat Desa Pedawa yang artinya menjadi buah bibir di lingkungan masyarakat Desa Pedawa, dan dari segi niskala maka orang tersebut akan mengalami kesakitan terus-menerus dalam keluarganya, kehidupan rumah tangga tidak harmonis, sulit memiliki keturunan.

b. Dampak Mebase Tegeh Pada Aspek Sistem Kepercayaan Masyarakat Desa Pedawa yang menyungsung Yos Embang

Konsepsi dan kepercayaan itu sendiri yang menggambarkan bahwa masyarakat Desa Pedawa yang menyungsung Yos Embang percaya terhadap upacara mebase tegeh sebagai tahap akhir dari rangkaian upacara perkawinan dimana memiliki simbol bahwa banten base tegeh merupakan simbol pengnganti anak perempuan mereka yang menikah keluar dari Yos Embang. Dampak mebase tegeh dalam aspek religi yang ditunjukkan untuk memperkokoh kepercayaan dinamisme yang didasarkan pada keyakinan akan adanya kekuatan gaib, yang terdiri dari berbagai kegiatan keagamaan yang berpedoman pada kepercayaan tersebut.

\section{SIMPULAN}

Berdasarkan ketentuan sistem perkawinan di Desa Pedawa bagi masyarakat yang menyungsung Yos Embang apabila anak perempuan mereka menikah keluar dari Yos Embang maka pihak keluarga dari pengantin laki-laki harus menebus dengan melaksankan upacara mebase tegeh pada saat ngunye ke rumah mempelai perempuan. Hal ini didasarai karena masyarakat Desa Pedawa yang menyungsung Yos Embang zaman dulu sangat sulit memiliki keturunan keturunan anak perempuan, dalam hal ini Yos Embang masih memiliki kepercayaan terhadap mitos tersebut. Adapun makna yang terkandung dari upacara mebase tegeh yaitu makan kekerabatan, makna religi, dan makna budaya. Selanjutnya terdapat dampak dari mebase tegeh yaitu dampak mebase tegeh terhadap kehidupan dalam kelurga dan masyarat, dampak mebase tegeh pada aspek sistem kepercayaan masyarakat desa pedawa yang menyungsung Yos Embang.

\section{REFERENSI}

Geertz, Clifford. 1992. Tafsir Kebudayaan. Yogyakarta: Kanisius Press.

Windia dkk, Wayan P. 2008.Perkawinan Pada Gelahang di Bali.Denpasar: Udayana University Press.

Heriyawati, Yanti. 2016. Seni Pertunjukkan Dan Ritual.Yogyakarta: Ombak. 
Riski dkk. 2014. "Simbol Dan Makna Pernikahan Ritual Pernikahan Adat Jawa Di Desa Sukomanah Kecamatan Purwodadi Kabupaten Purworejo". Yogyakarta.Jurnal Universitas Negeri Yogyakarta Volume 3 No. 7.

Pramana, I Dewa Gede Adi. 2019. Tradisi Naur Kelaci dalam Upacara Perkawinan di Desa Subaya, Kecamatan Kintamani, Bangli:Jurnal Humanis, Fakultas Ilmu Budaya Unud. Volume 23 No 1.

Pratama, Bayu Adi. 2018. Pernikahan Adat Jawa di Desa Desa Nengahan, Kecamatan Bayat, Kabupaten Kelaten: Surakarta. Universitas Sebelas Maret. Volume 2 No 1.

Sipayung, Frans Kurnia. 2015. Dinamika Sistem Upacara Perkawinan Batak Simalungun di Kabupaten Simalungun, Sumatra Utara Tahun 1950-2010: Jurnal Humanis Fakultas Ilmu Budaya Universitas Udayana. Volume 11. No 1.

Firmansyah dkk. 2017. "Kedudukan Anak Dalam Perkawinan Adat Ngerorod (Kawin Lari) di Desa Padang Sambian Kaja, Kecamatan Denpasar Barat, Denpasar". Semarang: Jurnal Universitas Diponegoro Volume 6 No.2: 2-3.

Dade, Yacobus Renabolo. 2012. Dinamika Belis dalam Adat Perkawinan Masyarakat Rote Ba'a di Kabupaten Mokdale, Kecamatan Lobalain, Kabupaten Rote Ndao.Program S1 Antropologi. Jurnal Universitas Udayana Volume 1 No.1
Manalu, Mely Tri Santy Br. 2013. Kebertahanan Perkawinan Ideal Menurut Suku Batak Karo di Kelurahan Kwala Bekala Padang Bulan Medan (Suatu Tinjauan Antropologi). Jurnal Humanis Unud Volume 2 No 1.

Hartawan, Dana Putra. 2017. Makna Ritual Nyepeg Sampi dalam Upacara Usaba Kawulu di Desa Adat Asak Kabupaten Karangasem. Jurnal Humanis, Fakultas Ilmu Budaya Unud Volume 21 No.1.

Kusmirayani, Luh Ayu. 2013. Perkawinan Pada Gelahang di Bali (Perspektif Antropologi): Jurnal Humanis Fakultas Sastra Unud. Volume 3.No. 1.

Cun Bay, Timoteus. 2015. Perkawinan Eksogami Rang Pada Masyarakat Desa Inelika, Kecamatan Bajawa, Kabupaten Ngada, Nusa Tenggara Timur: Jurnal Humanis Fakultas Sastra dan Budaya Unud. Volume 10.No. 1.

Dharmapatni, Desak Putu Diah. 2016. Adaptasi Wanita Islam Terhadap Lingkungan Suami (Studi Kasus Perkawinan Amalgamasi Wanita Islam dan Pria Hindu di Bali): Jurnal Humanis Fakultas Sastra dan Budaya Unud. Volume 15.No. 1.

Santoso. 2016. Hakekat Perkawinan Menurut Undang-Undang Perkawinan, Hukum Islam Dan Hukum Adat: UNISULA Semarang. Volume 7.No.2. 